\title{
Side-by-side connection of LCC-HVDC links to form a DC grid
}

\author{
Yingmei Liu ${ }^{1}$, Chuanyue $\mathrm{Li}^{2}$, Qing $\mathrm{Mu}^{2}$, Jun Liang ${ }^{2}$ \\ Electric Power Research Institute, Beijing, $\mathrm{China}^{1}$ \\ Cardiff University, Cardiff, $\mathrm{UK}^{2}$
}

\section{Acknowledgements}

Yingmei Liu's work is supported by Nature Science Foundation under the project 51128701. Chuanyue Li's work is supported by China Scholarship Council under the project 201408060016. The work of Qing Mu and Jun Liang is supported by EU FP7 Marie-Curie ITN under the project 317221 .

\section{Keywords}

«HVDC», «LCC-HVDC», «Sid-by-side connection»

\begin{abstract}
HVDC is suitable for bulk-power and long-distance transmission. Most of the existing HVDC systems are point-to-point LCC-HVDCs. By interconnecting existing LCC links can achieve more economical benefits and higher flexibility of power transfer. However, due to different voltage levels and control modes of these links, it is impossible to interconnect them together directly through dc cables. The side-by-side connection of LCC links using DC transformers at a geographic crossing point or close proximity between the LCC links is proposed. Such connection is to achieve the benefits of dc grid operation without incurring vast amount of costs by constructing new DC transmission lines but making full use of existing LCC lines. Two LCC links tied by a DC transformer are tested as a case study. The DC transformer based on full-bridge sub-module is designed for coping with power reversal, temporary DC and AC faults and reduced voltage operation. And its control system is designed to match the operation of LCC links.
\end{abstract}

\section{Introduction}

The EU and the G8 Heads of Government announced a target to reduce at least $80 \%$ of greenhouse gas emissions below 1990 levels by 2050 [1].To meet this target, the renewable energy especially wind power and solar power is considered as the main energy supply in the future. The idea of building a pan-European overlay DC grid also known as Supergrid covering the whole Europe,Middle East and North Asia is proposed to allow the massive integration of renewable sources [2][3]. The urbanization and industrialization of China has a great demand of electricity to support its economic growth. However, the geographical distribution of load and power source is highly uneven [4]. High voltage direct current (HVDC) technology has been required to transmit the demanded electricity, from the north and the west to the east.

HVDC is an efficient technology for long-distance and bulk-power transmission. It is considered as the key technology for Supergrid development. HVDC technology is categorised into two types, voltage source HVDC (VSC-HVDC) and line commutated HVDC (LCC-HVDC). VSC-HVDC is a new HVDC technology and its rating can only reach to $\pm 320 \mathrm{kV}$ and 1,000 MW[5] [5]. First VSCHVDC was put in commercial operation in 1997 at Gotland [6]. The drawbacks of LCC-HVDC, including power reversal with changing DC voltage polarity of the converters, no individual active and reactive control, no black-start capability, and commutation failure, make it less suitable for DC grid than VSC-HVDC [7][8][9].

LCC-HVDC has been put in operation for many decades and proven to be a mature and reliable technology. First commercial HVDC Gotland link based on Line Commuted Converter (LCC) was 
commissioned in 1954 [10]. To date, the majority of the HVDC transmission in service is LCCHVDC. In many parts of the world, the power demanding is growing. LCC-HVDC will still be the main choice for inland long-distance and bulk-power transmission [11]. In 2013, the longest LCCHVDC project was commissioned in Brazil named Rio Madeira. It is a $\pm 600 \mathrm{kV} 6,300 \mathrm{MW}$ HVDC project built to export electricity from remote hydro source to major load centers over $2375 \mathrm{~km}$. In 2016, the $\pm 800 \mathrm{kV}$ North-East Agra LCC-HVDC which will be the world's first multi-terminal ultrahigh HVDC link will be commissioned for hydropower transmission. China owns the most amount of LCC projects in the world. By 2015, 29 point-to-point LCC-HVDC projects will be in service, including the highest rating of $\pm 1100 \mathrm{kV} 10.5 \mathrm{GW}$ LCC-HVDC project [4].

The wide distribution of diverse energy sources and power demands, differing in different places especially in China [12], makes it possible that the characteristics of power source and load in some LCC links are complementary. The quickly increasing electricity demand gives a great challenge for Chinese power industry [13]. Wide interconnection of existing LCC links can bring the benefits on smoothing power transfer and compensating each other, increasing utilization of LCC links and avoiding constructing the new transmission system to meet the power demands. However, the disadvantages of complex control system of LCC links such as Voltage Dependent Current Limit (VDCL) [14], power reversal and commutation failure as mentioned previously, bring a challenge for the interconnections. DC transformers also named DC/DC converters are considered as the address for such interconnection to form a high efficient DC grid.

Inspired by back-to-back converters for two AC grids interconnection, this paper presents a side-byside connection for DC link interconnection using DC transformers based on Modular Multilevel Converter (MMC). Two MMCs are connected at AC side to perform one DC transformer, and the DC terminals are used to interconnect two LCC systems.

The aims of the side-by-side interconnection methods of LCC links are to maintain their own control modes, and exchange the power through the DC transformers. The H-bridge based DC transformer and control system are designed to cope with control system of LCC-HVDC, flexibly regulate the power between LCC-HVDC links, connect to various voltage levels, adapt the reversal of DC voltage polarity, and isolate disturbances. The interconnection point can be chosen according to geographical positions such as the crossing of LCC links to avoid the construction cost of new DC transmission lines.

\section{Characteristics of LCC-HVDC}

Unlike VSC-HVDC only regulates the current direction to reverse the power flow, LCC-HVDC has to change the voltage polarity. And the disturbances is not only the transient DC cable fault, LCC's famous commutation failure should be included. This failure is mainly caused by voltage dips due to AC faults.

For giving a clear explanation of power reversal, the basic module of a three-phase line-commutated converter is used, as shown in Fig.1.Fig. 2 gives the angle definitions. This six-pulse converter is able to operate on rectifier mode and inverter mode according to thyristors' applying fire angles $(\alpha)$.

When $\alpha<90^{\circ}$, the de voltage $\left(V_{d}\right)$ is positive. Under this condition, the converter works on rectifier mode to send the power to the dc side. Due to the unidirectional thyristors, the dc current $\left(I_{d}\right)$ can only flow out through positive port, and back through negative port. When $\alpha>90^{\circ}$, the dc voltage changes polarity. Under this condition, it works on inverter mode to absorb the power from the dc side. One LCC link consists of one rectifier as sending terminal and one inverter as receiving terminal. To ensure the power flow, the rectifier's positive port is connected to the inverter's negative port. And the rectifier's negative port is connected to the positive port. Under normal condition, the LCC link works at positive voltage level. During power reversal, the rectifier forces $\alpha$ to increase and finally works on inverter mode, the inverter forces $\alpha$ to decrease and finally works on rectifier mode. The LCC link works at negative voltage level. 
One commutation failure is introduced below. Fig. 2 gives the angle relationships when the current is being commutated from T1 to T3. Positive crossing and negative crossing are occurred between $V_{a}$ and $V_{b}$. After negative crossing, the voltage across $\mathrm{T} 1$ becomes positive. Thus a minimum extinction time $(\gamma)$ is required for the thyristor in conduction are full turn-off before negative cross. In practical thyristor converters, there is considerable ac side inductance $\left(L_{S}\right)$, such as transformer leakage reactance and the impedance in the ac grid. Thus commutation from one thyristor to the next cannot be instantaneous. If extinction angle is too small or the commutation process $(\mu)$ reaches negative crossing causing commutation stopping, this thyristor such as T1 will reconduct. When the other thyristor such as T4 connected to the same phase turns on, a short current also known as a commutation failure occurs. Continuous commutation failures may result in the collapse of the LCC link.

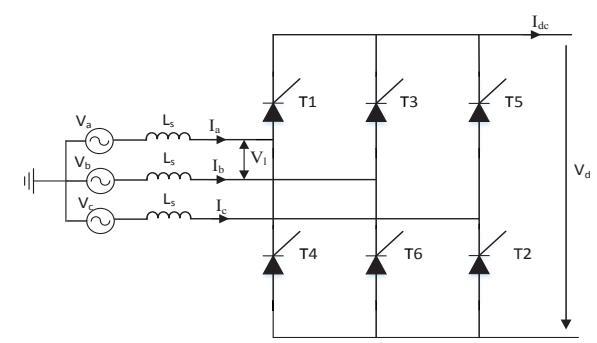

Fig. 1. 6-pulse converter

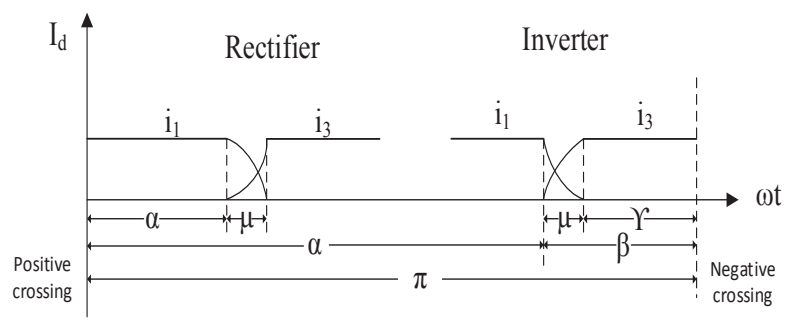

Fig. 2. The angle definitions for both rectifier and inverter

\section{System configuration}

\section{Description of the LCC link}

Two LCC links tied by one DC transformer are given for analysis, as shown in Figure 3. While the LCC link is derived from the 24-pulse Three Gorges-Changzhou $\pm 500 \mathrm{kV} 3000 \mathrm{MW}$ project based on bi-pole structure [15]. This link ties Central China Power system and East China Power System together. The power flow is decided by both demands of these two systems. During the most time of one year this link transfers power from Three Gorges power plant to East China Power System. In the winter, this link maintains its power flow during the peak time of the east and reverses its power flow during the valley time.

Actually, this 24-pulse bi-pole link consists of two 12-pulse asymmetrical monopoles witch are connected in series on the DC side and in parallel in the AC side. Middle point between two 12-pulse converters in series connection is grounded. Therefore, each terminal of the LCC link owns one $+500 \mathrm{kV}$ positive pole and one $-500 \mathrm{kV}$ negative pole. Actually, 12-pulse converter consists of 26 pulse bridges. They are connected in series on the dc side to provide the full DC voltage for one pole. Each 6-pulse bridge provides half DC voltage. And they are connected in parallel with two different types of transformers on the ac side. These two transformers, that one is star-delta connection and the other is star-star connection, provide a thirty degrees phase shift for the DC voltage. In theory, the 6pulse bridge as a basic converter is able to give a conversion between the ac and the dc. However, most converters use the 12-pulse converter rather than the 6-pulse converter in order to give a better harmonic performance.

The DC voltage of LCC is shown below:

$$
V_{d 1}=2 \times\left(1.35 V_{l} \cos \alpha-\frac{3}{\pi} X_{s} I_{d}\right)
$$

$V_{l}$ is the AC line-to-line voltage, $X_{\underline{S}}$ is the equivalent commutation inductance on the AC side, $\alpha$ is the fire angle.

The DC current is shown in equation (2) and equation (3):

$$
I_{d}=\frac{V_{d 1}-V_{d 2}}{R_{1}}
$$




$$
I_{D C I}=\frac{V_{I}-V_{A 11}}{R_{11}}
$$

$R_{1}$ is the resistance of the DC line, $R_{11}$ is an added resistance to ensure the power flow between the DC transformer and the LCC link, $V_{A 11}$ is the voltage on the connection point A11.

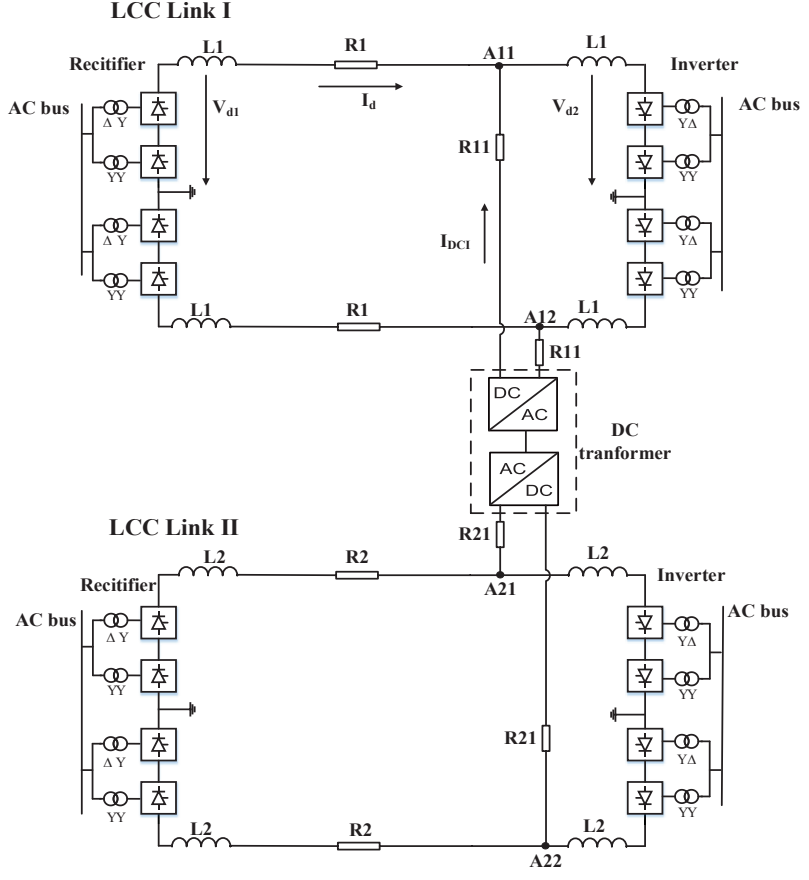

Fig. 3. Interconnection of two LCC links

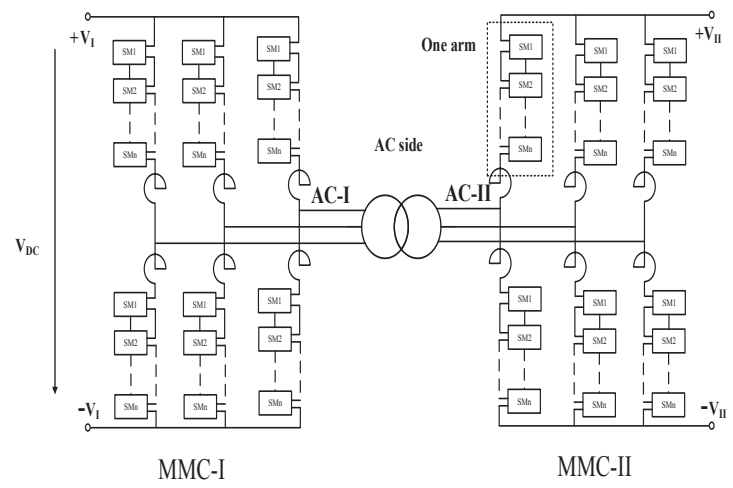

Fig. 4. Structure of the DC transformer

\section{Topology of the DC transformer}

A DC transformer is proposed to perform the side-by-side connection between these two LCC links. The DC transformer is able to absorb or support the power according to the demand of LCC links, and its structure is shown in Fig. 4. The DC power is transferred to AC power through MMC-I, then transferred back through MMC-II and vice versa. Each MMC has six arms, and each arm is consisted of $\mathrm{n}$ sub-modules (SM). Each SM can be seen as a controlled voltage source with three voltage levels $\left(+V_{S M}, 0,-V_{S M}\right)$. For a phase arm (one pair of upper arm and one lower arm), the number of turn-on $\mathrm{SM}$ is always same between the $\mathrm{DC}$ terminals to maintain the $\mathrm{DC}$ voltage. The $\mathrm{AC}$ terminal is connected to the midpoint of the phase arm. A switching sequence is given to SMs of the phase arm to build the $\mathrm{AC}$ voltage for the $\mathrm{AC}$ terminal. The $\mathrm{DC}$ voltage of one phase arm is shown below:

$$
V_{D C}=\sum_{i=1}^{N}\left(S_{u i} V_{S M}\right)+\sum_{i=1}^{N}\left(S_{l i} V_{S M}\right)
$$

$S_{u i}$ and $S_{l i}$ are the switching function of the SMs in the upper arm and lower arm. When the output voltage of one SM is positive, $S_{i}=1$. When the voltage is $0, S_{i}=0$. When the voltage is negative, $S_{i}=-1$.

Up to now, there are two types of SMs, half-bridge SM and full-bridge SM as shown in Fig.5. Both are able to achieve AC-to-DC or DC-to-AC conversion. Half-bridge SM is more commercial due to less IGBTs.. However, it is not able to follow negative voltage level. Full-bridge SM allows extra flexibility for different voltage level connection. The Full-bridge arrangement is capable of producing a three-state output voltage: $0,+V_{c},-V_{c}$, where $V_{c}$ is the capacitor voltage, as shown in Table I. Because the SM can give $-V_{c}$ output voltage, the DC transformer is able to change the voltage polarity to follow power reversal of LCC-HVDC. 


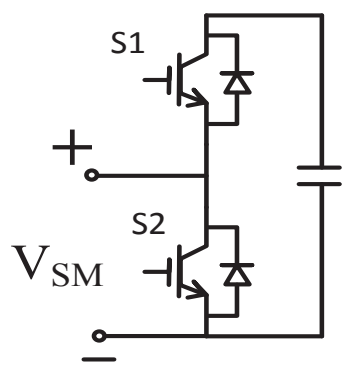

(a)

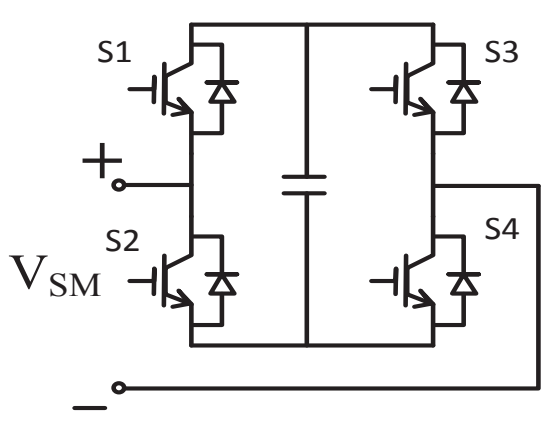

(b)

Fig. 5. (a)Half-bridge SM (b)Full-bridge SM

Table I: Full-bridge SM's output voltage with different switching states

\begin{tabular}{|c|c|c|c|c|}
\hline $\mathrm{S} 1$ & $\mathrm{~S} 2$ & $\mathrm{~S} 3$ & $\mathrm{~S} 4$ & $V_{S M}$ \\
\hline on & off & off & on & $V_{C}$ \\
\hline off & on & on & off & $-V_{C}$ \\
\hline on & off & on & off & 0 \\
\hline off & on & off & on & 0 \\
\hline
\end{tabular}

\section{Control system}

The inverters of Link I and Link II are to control the voltages. The rectifiers of Link I and Link II are to control the current. The DC transformer is to maintain the power of Link I's inverter.

Due to the fixed current flow direction of LCC links, LCC links are designed to regulate the voltage to achieve flexible power flow. The power absorbed or supported by the DC transformer changes the power flow in the LCC links. Take LinkI's positive pole as an example. Before side-by-side connection, currents on the left of point A11 and on the right maintain same. After side-by-side connection, currents are different, because a part of current is injected or taken into LinkI through point A11 by the DC transformer. Therefore, the control system of LCC links should be modified to adapt this change.

\section{Current order modification of LCC links}

Not only the parameters but the control systems of both LCC links are same. For LCC links, the rectifiers regulate the current through current control under normal operation. Voltage dependent current order limit (VDCOL) is added to assist the AC system in recovering from faults, as shown in Fig. 6(a).

It may result in commutation failure in the inverter when extinction angle is too small. Therefore, the inverter prefers controlling the voltage through constant extinction angle control to keep the extinction angle being in safe range, as shown in Fig. 6(b).

Normally, the rectifier's DC current order referred to as $I_{\text {order }}$ in Fig. 6(a) comes from the inverter side. Due to side-by-side connection, the taken point of DC current order is changed to the rectifier side to ensure the stable operation of the whole system.
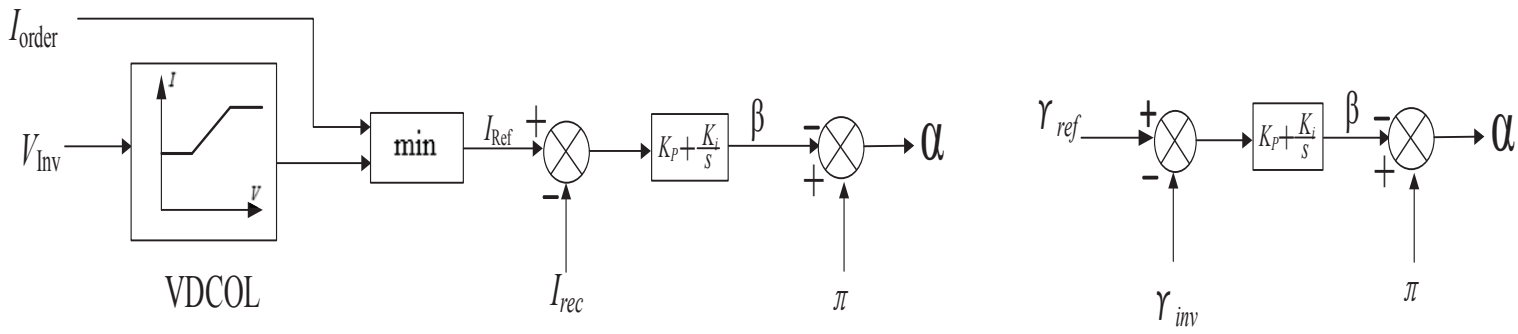
(a)

(b)

Fig. 6. (a)Rectifier control (b)Inverter control

\section{Control system of the DC transformer}

Proper parameters have to be controlled by the DC transformer to achieve power exchange between LCC links, protect the LCC link from the disturbances of the other, follow the power reversal, and maintain LCC's normal operation.

Power flows in positive pole and negative pole are same, thus only power flow in positive pole is shown in Fig. 7 to identify the proper parameters. $V_{A 11}$ and $V_{A 21}$ are the voltages of connection points as shown in Fig. 3, and are controlled by LCC links. The DC power and current on MMC-I and MMCII are shown below:

$$
\begin{gathered}
P_{I}=V_{I} \times I_{I} \\
I_{I}=\frac{V_{I}-V_{A 11}}{R_{11}} \\
P_{I I}=V_{I I} \times I_{I I} \\
I_{I I}=\frac{V_{A 21}-V_{I I}}{R_{21}}
\end{gathered}
$$

$P_{I}, P_{I I}, V_{I}, V_{I I}$ represent the DC powers and voltages of two MMCs.

Power exchange between AC side and DC side are shown below:

$$
\begin{aligned}
P_{I} & =P_{I_{-} A C} \\
P_{I I} & =P_{I_{-} A C}
\end{aligned}
$$

The power on ac side is shown below:

$$
\begin{aligned}
& P_{I_{-} A C}=\frac{V_{2} V_{1}}{Z} \cos \left(\theta-\phi_{2}+\phi_{1}\right)-\frac{V_{1}^{2}}{Z} \cos \theta \\
& Q_{I_{-} A C}=\frac{V_{2} V_{1}}{Z} \sin \left(\theta-\phi_{2}+\phi_{1}\right)-\frac{V_{1}^{2}}{Z} \sin \theta
\end{aligned}
$$

$P_{A C I}$ and $Q_{A C I}$ are the active power and reactive of the ac side on MMC-I.

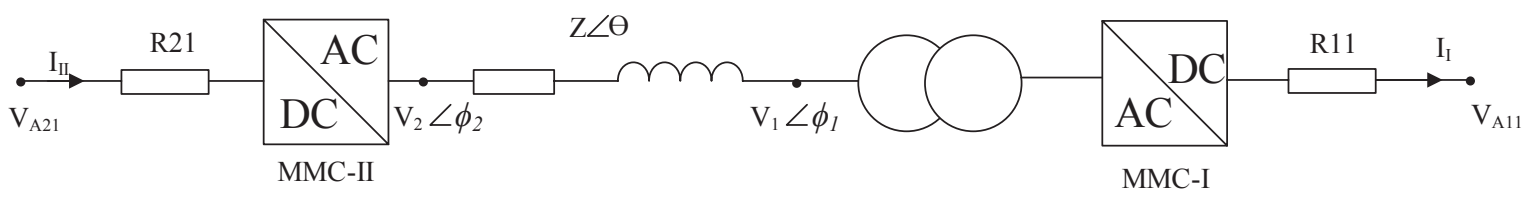

Fig. 7. Power flow in side-by-side connection

From the power flow analysis as mentioned before, MMC-I is designed to control the power absorbed from Link II. The power control of MMC-I aims to maintain the Link I's power support. Therefore, the active power reference $P_{I_{-} r e f}$ comes from power shortage between the power $\left(P_{I_{-} R E C}\right)$ supported by rectifier of Link I and the power $\left(P_{I_{-} I N V}\right)$ demanded by inverter of Link I. MMC-II is designed to build the AC voltage in order to ensure the power exchange between MMC-I and MMC-II and finally achieve power transmission from Link II to Link I. The control diagrams are shown in Fig. 8. In Fig. 8(a), outer loop includes active power control and reactive power control with PI controllers to control the power flows between Link I and Link II. Outer loop produces d-and q- axis current reference for inner current loop. The AC frequency is set to a constant value. In Fig. 8(b), outer loop includes magnitude control and phase control of AC side voltage with proportion-integral (PI) controllers to track the AC side voltage of MMC-II. And a phase locked loop (PLL) is used to track the AC frequency in MMC-I side. 


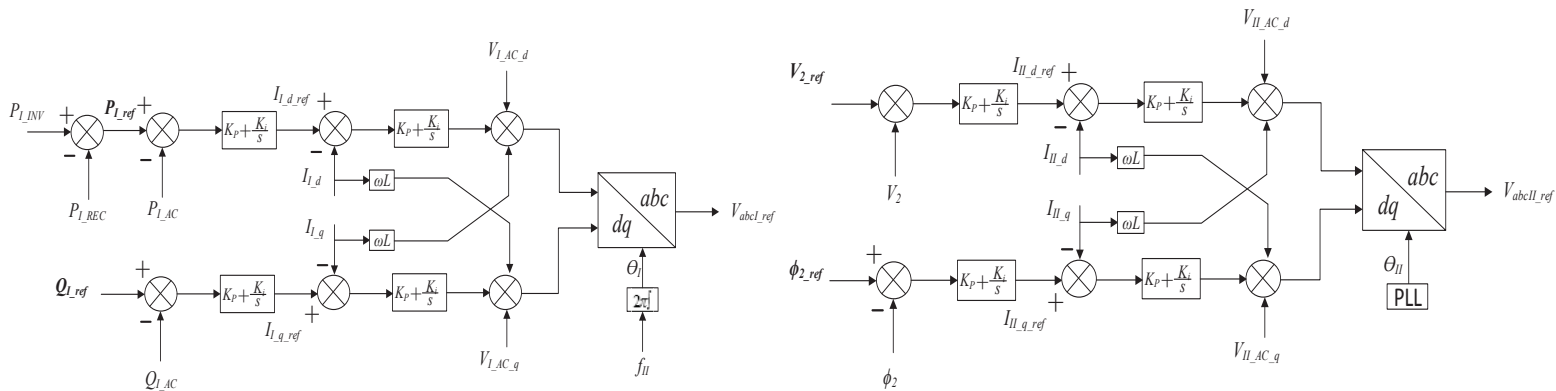

(a)

(b)

Fig. 8. (a) MMC-I control system (b) MMC-II control system

\section{Simulation study}

This side-by-side connection system as shown in Fig. 3 is simulated in Advanced Digital Power System Simulator (ADPSS) [16]. The rating of the DC transformer is shown in Table II. Link I works at $\pm 500 \mathrm{kV}, 3000 \mathrm{MW}$, Link II works at $\pm 500 \mathrm{kV}, 1800 \mathrm{MW}$. The simulation results of the positive poles are shown and $500 \mathrm{kV}, 200 \mathrm{~A}$ are chosen as the base value. Four cases are designed to verify the feasibility of this DC transformer.

\section{Table II: Data of the DC transformer}

\begin{tabular}{|c|c|}
\hline DC side voltage level & $\pm 500 \mathrm{kV}$ \\
\hline AC side voltage level & $500 \mathrm{kV}, 50 \mathrm{~Hz}$ \\
\hline Power rating & $400 \mathrm{MW}$ \\
\hline SM capacitance & $2.1 \mu \mathrm{F}$ \\
\hline Number of sub-modules per arm & 200 \\
\hline Arm inductance & $70 \mathrm{mH}$ \\
\hline Transformer Ratio & $500 \mathrm{kV} / 550 \mathrm{kV}$ \\
\hline
\end{tabular}

\section{Case 1: power regulation}

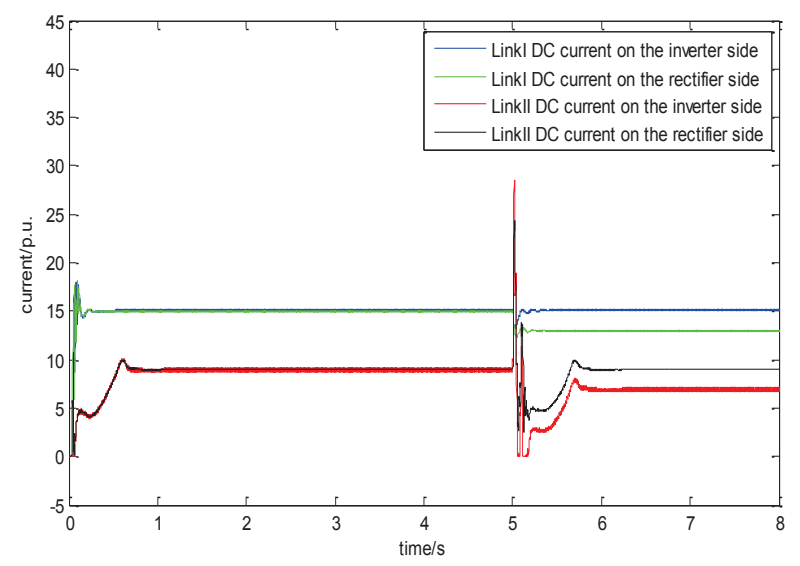

(a)

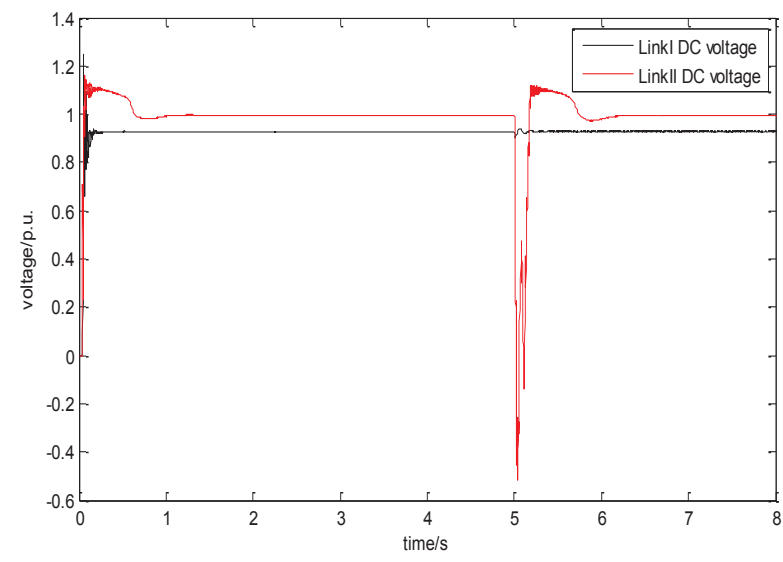

(b)

Fig. 9. Power absorb from Link II

Fig. 9(a) shows that before 5s, the power support of Link I follows its power demand at 3000MW level. There is no power exchange between these two links. At $5 \mathrm{~s}$, the rectifier of Link I reduces its current to 13 p.u. In order to maintain the power supply to the inverter of Link I, 2 p.u. current is absorbed from Link II and the current of Link I inverter side is kept at 15p.u. Fig. 9(b) shows that during power absorb, the DC transformer protects the DC voltage of Link I from the disturbance of Link II. 
Case 2: different voltage level connection

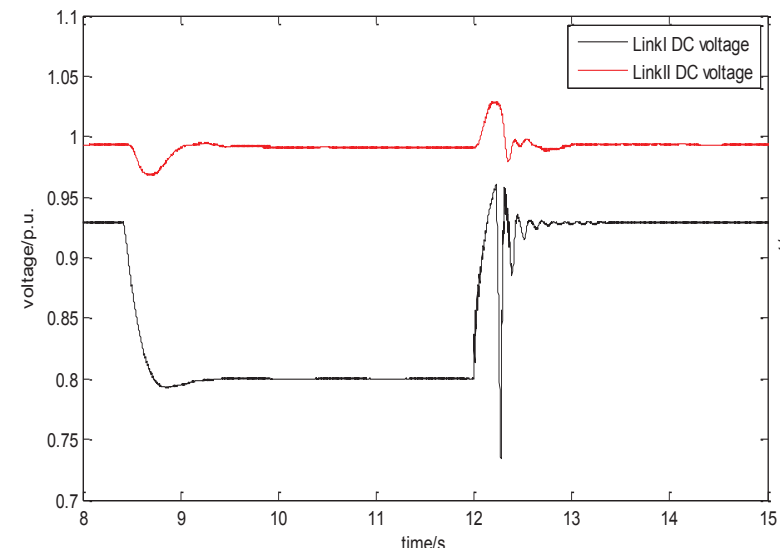

(a)

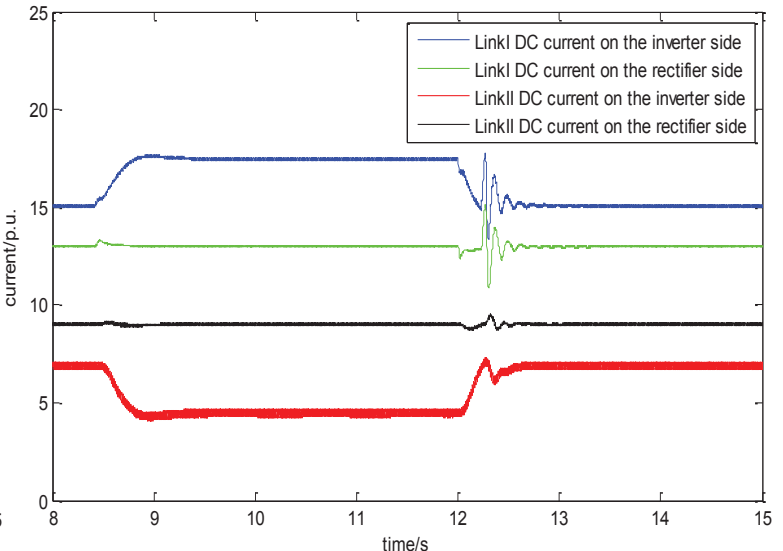

(b)

Fig. 10 Reduced voltage operation

As shown in fig. 10(a), Link II goes into reduced voltage operation at 8.5s. The voltage drops from 0.93 p.u. to 0.78 p.u for $3.5 \mathrm{~s}$. Thanks to the DC transformer, the voltage of Link II is maintained. As shown in Fig. 10(b), due to the voltage reduction of Link I, the receiving power is reduced. The DC transformer increases Link I's DC current on the inverter side to maintain the receiving power at $3000 \mathrm{MW}$. When the voltage of Link I goes back to normal level at 12s, the current absorbed from Link II is reduced to 2 p.u. .

\section{Case 3: power regulation under power reversal condition}

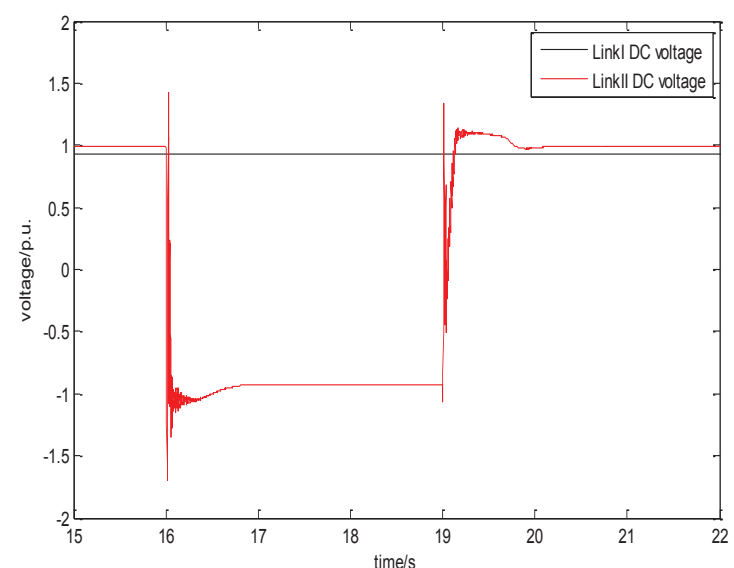

(a)

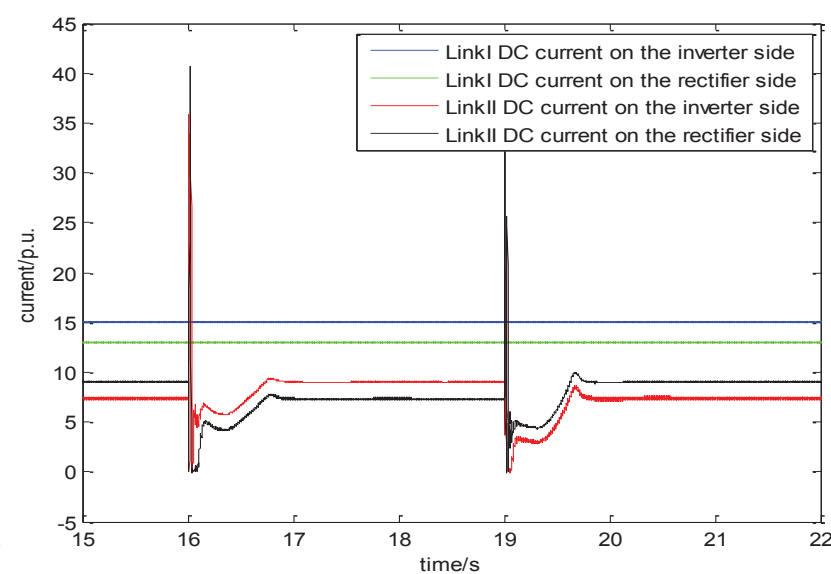

(b)

Fig. 11. Power reversal of Link II

As shown in Fig. 11(a), the DC voltage of Link II is reversed at 16s aiming to reverse the power flow. At 16s, the inverter of Link II takes over the current control and rectifier begins to regulate the voltage at -0.93 p.u. . AS shown in Fig. 11(b),the DC current on the inverter side of Link II is increase to 9 p.u. by inverter. Therefore, the same amount of power is transferred back. And the same amount of power is supported to Link I by DC transformer. It is obvious from both figures that the Link I still maintain its normal operation. The power reversal of Link II finishes at 19s. 


\section{Case 4: isolation of disturbances}

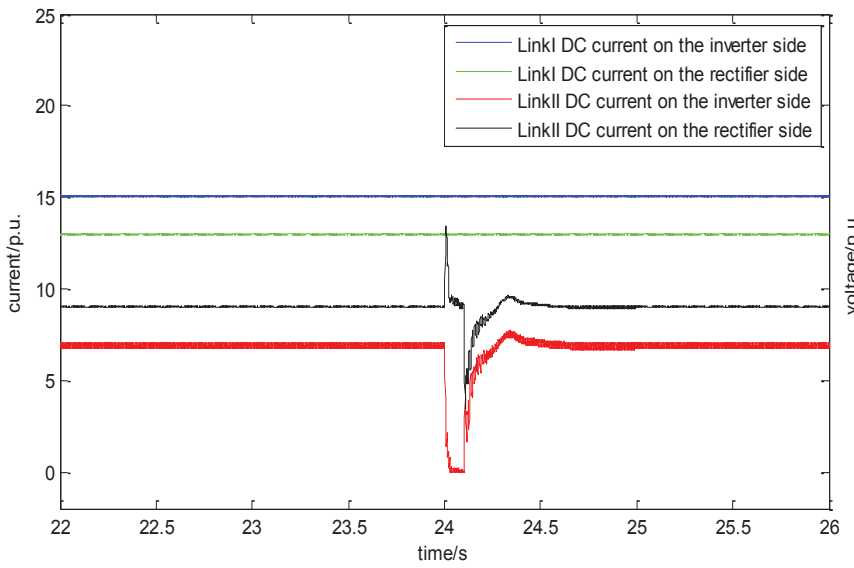

(a)

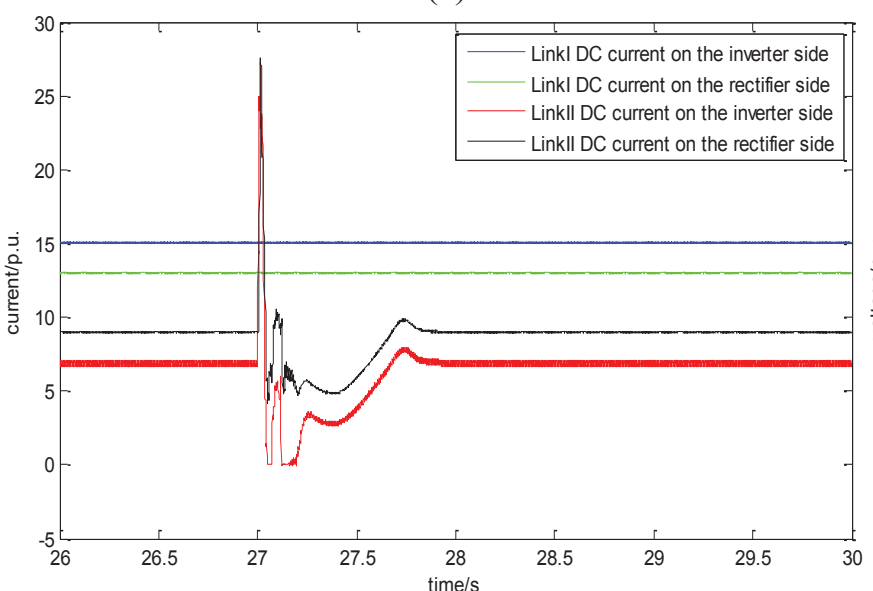

(c)

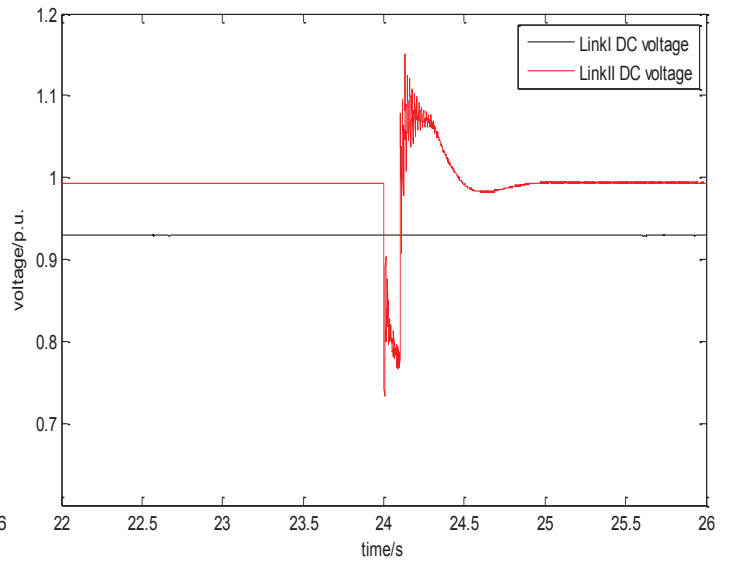

(b)

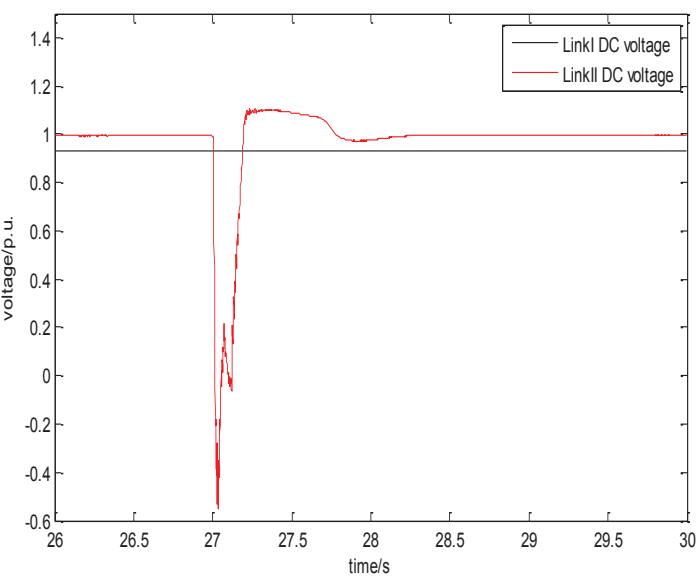

(d)

Fig. 13. 100ms AC fault and DC fault applied on Link II

In this case, both temporary DC and AC faults are applied as the disturbances. The DC fault occurs on the line of Link II the AC fault occurs on the AC side of Link II's inverter. As shown in Fig. 13(a) and (b), when the DC faults occurs at 24s, the DC current of Link II's inverter side reaches to 0, which means the power flow is stopped. As shown in Fig. 14(a) and (b), when the AC faults occurs at 27s, the normal operation of Link II is greatly disturbed. The voltage of Link II drop to nearly -0.6 p.u.. However, both faults on Link II do not influence the operation of Link I due to the isolation of the DC transformer. And the DC transformer still absorbs power from Link II to follow the demand of Link I's inverter

\section{Conclusion}

The side-by-side connection is developed using a DC transformer to interconnect two LCC links. The structure and control system of the DC transformer are developed. Such DC transformer can regulate the power flow flexibly between LCC links under normal operation and power reversal condition. Even the LCC link is in low voltage operation, the DC transformer still works properly and maintains the power in the other link at desired level. Disturbances caused by DC faults and AC faults are isolated by this DC transformer and keep the unfaulted link at normal operation.

\section{Reference}

[1] Foundation European Climate: Roadmap 2050: a practical guide to a prosperous, low- carbon Europe, Tech. Rep., April, 2010.

[2] Dii: Desert Power : Getting Started, Tech. Rep., June 2013.

[3] Friend Of the Supergrid: Supergrid preparatory phase : review of existing studies and recommendations to 
move forwards, Tech. Rep., March 2014.

[4] Lin C., Hua F. and Jian H.: HVDC development and its reliability in China, IEEE Power Eng. Soc. Gen. Meeting, Vancouver, BC, July 2013.

[5] Adapa R.: High-Wire Act: HVdc Technology: The State of the Art, IEEE Power and Energy Magazine, vol. 10, no. 6, pp. 18-29, NOV.-DEC. 2012.

[6] Axelsson U., Holm A., Liljegren C. and Eriksson K.: GotlandHVDC light transmission-world's first commercial small scale de transmission, CIRED Conf., Nice, France, May 1999.

[7] Ergun H., Beerten J. and Hertem D. V.: Building a new overlay grid for Europe, IEEE Power. Eng. Soc. Gen. Meeting, San Diego, CA, July 2012.

[8] Friends of the Supergrid: Roadmap to the Supergrid Technologies, Tech. Rep., March 2012.

[9] Liang J., Jing T., Gomis-Bellmunt O., Ekanayake J. and Jenkins N.: Operation and control of multiterminal HVDC transmission for offshore wind farms, Power Delivery, IEEE Transactions, vol. 26, no. 4, pp. 25962604, June 2011.

[10] Tiku D.: DC power transmission: mercury-arc to thyristor HVDC Valves [History], Power and Energy Magazine, IEEE, vol. 12, no. 2, pp. 76-96, March-April 2014.

[11] Kirby N. M.: HVDC system solutions, Transmission and Distribution Conference and Exposition (T\&D), 2012 IEEE PES, Orlando, FL, May 2012.

[12] Chen S., Huang F., Zhang B. H, Ni Y., Shi L. and Xu Z.: Fast development of Chinese power industry and its impacts on power system R\&D, Power Eng. Soc. Gen. Meeting, Tampa, FL, Jun. 2007.

[13] Fu S. and Zhong J.: Hydropower in China," IEEE Power Enery Mag., vol. 6, no. 4, pp. 47-51, Jul.-Aug. 2008.

[14] Padiyar K. R.: HVDC power transmission systems, Tunbridge Wells, UK: New Academic Science, 2011.

[15] Liu Z.: Design features of Three Gorges-Changzhou \pm 500 kV HVDC Project, IEEE Power Eng. Soc. Winer Meeting, Jan. 2000.

[16] Tian F., Li Y., Zhou X. and e. al.: Research, development and application of advanced digital power system simulator, Power System Technology, vol. 32, no. 22, pp. 17-22, 2008. 